\title{
Implications Of Environmental Factors On The Productivity of Selected Small And Medium Scale Enterprises In Rivers-State
}

\author{
Jonah Charles Tambari \\ Department of Management \\ Faculty of Management Sciences \\ University of Portharcourt, Rivers State, Nigeria
}

\author{
Aginah Chioma \\ Department of Business Administration and Management, \\ Akanu Ibiam Federal Polytechnic, Unwana, Afikpo, Ebonyi State \\ Martins C Ononogbo \\ Department of Business Management, \\ IMO State University, Owerri, Nigeria
}

\begin{abstract}
This study is on implications of environmental factors on the productivity of small and medium scale enterprises in River-state: a study of selected SMES in Portharcourt. The study took a descriptive survey approach and relied on a five point likert scale questionnaire as its major source of data. The study covered a population of 150 members of staff of three SMEs selected from the three senatorial zones of Rivers-state from where a sample of 124 respondents was drawn using purposive sampling technique. The data gathered was analyzed using multiple regressions with the aid of 20.0 version of the statistical package for social sciences (SPSS 20.0). Results obtained from the joint test shows that environmental factors affects the productivity of SMEs. However, the results of the individual test suggest that the implications of economic and political environmental factors are severely felt by SMEs than the socio-cultural factors. Based on the results obtained, the paper drew three conclusions and advanced three recommendations among which were; that SMEs should strategically engage in constant monitoring and conducting of environmental scanning, SMEs should learn to align their operational strategies with present market and environmental realities. This calls for a regular update and adjustment in strategies and that Government should provide an urgent safety net for SMEs against undue taxation and other harsh economic policies that tend to hamper their productivity
\end{abstract}

Keywords: business environments, economic, political, productivity, SMEs, socio-cultural

\section{INTRODUCTION}

The operational environment of business across the globe is characterized with complexity and dynamism. Business environment is said to be complex because there are many inter-playing factors, and dynamic because it is in a constant change. All organizations are seen as an open system. This presupposes that they interact with their environment; hence, they affect and are affected by events and trends in their environment. Small and medium scale enterprises in Nigeria are one of the major hits in the changes in operational environment; this may not be unconnected with their lack of capacity to compete with large firms and imported products from other countries where the cost of production is cheaper especially those from the Asian countries, they enjoy less protection from the government and are exposed to lack of social capital, all these creates pressure on the productivity of SMEs in Nigeria. The situation of SMEs in Nigeria appears more pathetic as government economic policies are changed at ease without concern to its industrial development impact, the political terrain has proven to be unstable 
and the lack of policy direction and investment on technological development and sociocultural affairs has created a knowledge gap in the economy that hampers the productivity of SMEs. Emphasizing the significance of business environment, Oginni (2010), posits that no business organization can operate successfully in isolation without dependence on supportive institutions, variables and factors i.e business organization exists and operates within an environment where there is complex interplay in terms of activities as well as networks of relationship between and among human resources, material resources and other systems. Business environment according to Oginni and Faseyiu (2012) is expressed as the sum total of the external forces that influences individuals, businesses and communities. In the views of Adebayo et al (2005), environment is summarized as the surrounding of a phenomenon which from time dictate and shape the direction. Business organization does not operate in vacuum; it operates within the environment where the production and distribution of goods and services are carried out.

\section{Statement of the Problem}

For organizations to achieve their goals, they must do that within allowable resources of the environment. The economy provides the needed market situation and funding for businesses, when the economic factors in the environment does not support business performance, the firm may not be able to produce profitably. Peace is a sine-quanon for productivity, the political environment especially in developing economies like Nigeria may be exposed to violence and frequent change of government, and this may lead to change in both economic and public policies. This makes it difficult for SMEs to accurately forecast and plan their operations, this hinders productivity.

\section{Objectives of the Study}

The general objective of this study is to the impact of talent management on the performance of business organizations. The specific objectives are as follows:

1. To find out the implications of economic environment on the effectiveness of SMEs in Nigeria.

2. To examine the implications of political environment on the efficiency of SMEs in Nigeria.

3. To examine the implications of socio-cultural environment on SMEs competitiveness

\section{Research Questions}

This paper was guided by the following questions;

1. What are the implications of economic environment on the effectiveness of SMEs in Nigeria?

2. What are the implications of political environment on the efficiency of SMEs in Nigeria?

3. What are the implications of socio-cultural environment on SMEs competitiveness?

\section{Hypotheses}

The following hypotheses were raised for this study;

Ho1: economic environment does not have significant implications on the effectiveness of SMEs in Nigeria.

Ho2: political environment does not have significant implications on efficiency of SMEs in Nigeria.

Ho3: socio-cultural environment does not have significant implications on the competitiveness of SMEs in Nigeria. 


\section{Business Environment}

\section{REVIEW OF RELATED LITERATURE}

The concept of business environment according to the business dictionary (2013), can be defined as the combination of internal and external factors that influence a company's operating situation. The business environment can include factors such as: clients and suppliers; its competition and owners; improvements in technology; laws and government activities; markets, social and economic trends. Ask.com (2013) defines business environment as the physical and operational factors, both internal and external, that affect the flow of activities in a business. They include; customers, competitors, suppliers, distributors, industry trends, substitutes, regulations, government activities, the economy, demographics, social and cultural factors, innovations and technological developments. A business is influenced by the environment in which it operates and the success of any business is dependent on its ability to adapt to its environment. The complexity of this reality for business owners is compounded by the fact that there are many different environments that each business operates in. There is the macro environment, which in today's global economy refers to the whole world, where events often indirectly impact on businesses and there is the microenvironment, local events and circumstances which directly affect and interact with a business. (GIBS, 2013). A business' environment influences the functioning of the business system. Therefore, a business environment may be defined as all those conditions and forces which are external to the business and are beyond the individual business unit, but they all operate within it. These forces are customers, creditors, competitors, government, socio-cultural organizations, political parties' national and international organizations etc. Some of these forces affect the business directly whilst some others have an indirect effect on the business (Blurtit, 2013). According to the Institute of Chartered Accountants study pack (2009) business environment can be defined as a set of factors or conditions that are external to the business but which have influence on the operations of the business enterprise. External in the context means that these factors or forces are not usually within the control of the business enterprise. It further describes it as the web of forces which form the setting in which the firm makes its decisions.

\section{Nature of Business Environment}

Saritha (2012) gave the followings as the nature of business environment;

(1) Totality of External Forces: Business environment is the sum totals of all those factors/forces which are available outside the business and over which the business has no control. It is the group of many such forces that is why, its nature is of totality.

(2) Specific and General Forces: The forces present outside the business can be divided into two parts - specific and general.

(i) Specific: These forces affect the firms of an industry separately, e.g., customers, suppliers, competitive firms, investors, etc.

(ii) General: These forces affect all the firms of an industry equally, e.g., social, political, legal and technical situations.

(3) Interrelatedness: The different factors of business environment are co-related. For example, let us suppose that there is a change in the import-export policy with the coming of a new government.

In this case, the coming of new government to power and change in the import-export policy are political and economic changes respectively. Thus, a change in one factor affects the other factor.

(4) Dynamic Nature: As is clear that environment is a mixture of many factors and changes in 
some or the other factors continue to take place. Therefore, it is said that business environment is dynamic.

(5) Uncertainty: Nothing can be said with any amount of certainty about the factors of the business environment because they continue to change quickly. The professional people who determine the business strategy take into consideration the likely changes beforehand. But this is a risky job. For example, technical changes are very rapid. Nobody can anticipate the possibility of these swift technical changes. Anything can happen, anytime. The same is the situation of fashion.

(6) Complexity: Environment comprises of many factors. All these factors are related to each other. Therefore, their individual effect on the business cannot be recognized. This is perhaps the reason which makes it difficult for the business to face them.

(7) Relativity: Business environment is related to the local conditions and this is the reason as to why the business environment happens to be different in different countries and different even in the same country at different places.

Source:http://www.yourarticlelibrary.com/management/7-important-characteristics-ofbusiness-environment/891/

\section{Factors in Business Environment}

There are many factors in business environment. But in this paper, we shall review only those that affect the objectives of the study

Economic: Ogundele (2005) says that is vital concern to an organization. He further said that, the economic environment goes a long way to determine and define the opportunities for an organization; this is because an expanding economy provides operational scope for the organizational existence as well as for the establishment of new ones. However, a period of recession can bring about failures and probably liquidation of the organization. It is of paramount importance that the management should be able to distinguish between short-run phenomena and more fundamental changes in its assessment of the overall economy.

Political: The political environment is viewed via the legal framework where the organization operates and this is done through the laws and regulations that guide the operations of the business in question. The political stability of the environment is also a necessity for effective and efficient operation of the business. The management of the organization must take cognizance of these constraints, actual and potential, a nd seek out the implications for the business organisation from legal advisers (Ogundele, 2005).

Socio-Cultural Factors: Wetherly (2011) described the socio-cultural environment as consisting of everything that is not contained within the economy or political system. According to him, socio-cultural setting is made up of collection of activities, and the relationships people engage in their personal and private lives which include population features, age, ethnicity, religion, values, attitude, lifestyles and associates. These environmentally relevant patterns of behaviour lead to the creation of different cultural values in different societies, some of which influence the decision to create new businesses.

\section{Small and Medium Scale Enterprises}

According to Olorunshola (2003), the concept of SMEs is relative and dynamic. The characteristics of SMEs are uncertainty, innovation and evolution. A firm understanding of SMEs world required a good knowledge of its features. In Nigeria SMEs are usually small in size 
and lack large organizational structure and management culture while the urban SMEs are more structural, the rural ones are less structured. This represents one of the most important characteristic of SMEs in Nigeria. SMEs are in most cases a one man business or partnerships enterprise, although they may be registered as limited liability company, (Udechukay, 2003). Olurunshola (2003) affirmed that this ownership style has led small and main enterprise to have a simple management structure and make it easiest to manage than that of large firms, and few numbers of staff and in some cases low level of education by some owners of SMEs. SMEs almost shave the same characteristic with a sole proprietorship in that, there is no legal personality between the SMEs and their owners, which means that the life span of SMEs depends on the life of the owners; when the owner dies, if not properly taken care by the estate the business will die with the owner(s) Another feature of the SMEs sector in some countries is its heterogeneous nature, ranging from retail outlets to hugely paid professionals and substantially manufactured organization small and medium enterprise are also likely to vary in organizational form, from sole proprietorship (one man business), scale corporations (public or private), professionals and partnerships. According to the World Bank (2013), SMEs are defined based on the size of the enterprise in terms of the total number of employees and/ or total assets value. SMEs and large firms can be differentiated based on the aforementioned criteria. However, the definition of SMEs can be viewed from different perspectives, depending on the organization or country. In Nigeria SMEs are defined as the firms that employ fewer than 200 employees and have less than 500 million Naira worth of total assets, excluding land and building (SMEDAN, 2012). Specifically, small enterprises refer to firms with employees between 10 to 49 and have N5m to less than N50m assets excluding land and building. Firms with employees between 50 to 199 and have N50m to less than N500m assets excluding land and building is referred to as medium enterprises

\section{Problems of SMEs in Nigeria}

The fact that SMEs have not made the desired impact on the Nigerian economy in spite of all the efforts and support of succeeding administrations and governments gives a cause for concern. It underscores the belief that there exists fundamental issues or problems, which confront SMEs but which hitherto have either not been addressed at all or have not been wholesomely tackled.

A review of literature reveals indeed the following plethora of problems, which are enormous, fundamental and far-reaching:

1. Inadequate, inefficient, and at times, non-functional infrastructural facilities, which tend to escalate costs of operation as SMEs are forced to resort to private provisioning of utilities such as road, water, electricity, transportation, communication, etc.

2. Bureaucratic bottlenecks and inefficiency in the administration of incentives and support facilities provided by the government. These discourage would-be entrepreneurs of SMEs while stifling existing ones.

3. Lack of easy access to funding/credits, which can be traceable to the reluctance of banks to extend credit to them owing, among others, to poor and inadequate documentation of business proposals, lack of appropriate and adequate collateral, high cost of administration and management of small loans as well as high interest rates.

4. Discrimination from banks, which are averse to the risk of lending to SMEs especially start-ups

5. High cost of packaging appropriate business proposals

6. Uneven competition arising from import tariffs, which at times favor imported finished products

7. Lack of access to appropriate technology as well as near absence of research and development

8. High dependence on imported raw materials with the attendant high foreign exchange 
cost and scarcity at times

9. Weak demand for products, arising from low and dwindling consumer purchasing power aggravated by lack of patronage of locally produced goods by the general-public as well as those in authority.

10. Unfair trade practices characterized by the dumping and importation of substandard goods by unscrupulous businessmen. This situation is currently being aggravated by the effect of globalization and trade liberalization, which make it difficult for SMEs to compete even in local/home markets.

11. Weakness in organization, marketing, information-usage, processing and retrieval, personnel management, accounting records and processing, etc. arising from the dearth of such skills in most SMEs due to inadequate educational and technical background on the part of the SME promoters and their staff.

12. High incidence of multiplicity of regulatory agencies, taxes and levies that result in high cost of doing business and discourage entrepreneurs. This is due to the absence of a harmonized and gazette tax regime, which would enable manufacturers to build in recognized and approved levies and taxes payable.

13. Widespread corruption and harassment of SMEs by some agencies of government over unauthorized levies and charges

14. Absence of long-term finance to fund capital assets and equipment under project finance for SMEs

15. The lack of scientific and technological knowledge and know-how, i.e. the prevalence of poor intellectual capital resources, which manifest as:

i. Lack of equipment, which have to be imported most times at great cost (capital flight) and which would require expatriate skills to be purchased at high costs.

ii. Lack of process technology, design, patents, etc., which may involve payment of royalties, technology transfer fees, etc. and heavy capital outlay.

iii. Lack of technical skills in the form of technological and strategic capability

iv. Inability to meet stringent international quality standards, a subtle trade barrier set up by some developed countries in the guise of environmental or health standards. A relevant example is the

impending ban of marine foods, vegetables, fruits and other agricultural products from Africa into the United States of America markets.

v. The inability to penetrate and compete favorably in export markets either because of poor quality of products, ignorance of export market strategies and networks or lack of appropriate mechanism and technology to process, preserve and package the products for export.

16. Lack of initiative and administrative framework or linkage to support and sustain SMEs' development, which to a large extent, is also a reflection of poor technological capability or intellectual resource

17. Lack of appropriate and adequate managerial and entrepreneurial skills with the attendant lack of strategic plan, business plan, succession plan, adequate organizational set-up, transparent operational system, etc on the part of many founders and managers of SMEs in Nigeria. As a fallout of this, many of the SME promoters purchase obsolete and inefficient equipment thereby setting the stage $a b$ initio for lower level productivity as well as substandard product quality with dire repercussions on product output and market penetration and acceptance.

\section{EMPIRICAL REVIEW}

Chikwe, Joel and Achiole (2015), examined the impact of regulatory environment on the effectiveness of small and medium scale enterprises. The study employed a survey approach 
and used the questionnaire as its major source of data collection. In order to guide the study, two research questions and hypotheses that are consistent with the objectives of the study were raised. The population of study consists of 105 staff of selected five small and medium scale enterprises in Owerri. The researchers used purposive sampling technique to select 89 members of staff as the sampled unit. The mean score $X$ was the tool for data analysis, and from the findings, the researchers concludes that regulatory environment has significant impact on business competitiveness and innovativeness which were used to proxy effectiveness of small and medium scale enterprises. Based on the findings also, the researchers among others recommended that consultation between SME regulators and operators of SMEs can help address some of the harsh consequences of the regulatory environment. Felicia et al (2014), studied effects of socio-cultural realities on the Nigerian small and medium sized enterprises (SMES): case of small and medium sized enterprises in Lagos state. The objectives of this paper are in two-folds, namely (i) identify socio-cultural realities in the SME business environment in Nigeria and; (ii) examine the impact of these factors (in i) on the development of SMEs. Sociocultural realities were measured from three major factors, namely attitude; religion and values: each of these factors were further categorized into several level of constructs. Responses from ten (10) SME owners/representatives in the five (5) major districts of Lagos state identified the socio-cultural realities as key factors affecting their businesses. They recommended a further research to further establish whether these results reflect the general condition in other states of Nigeria. Using cost technical and allocative efficiency scores, Lassana and Abdoulaye (2013), assessed the impact of electricity outages on SME enterprise productivity in Senegal. Results based on survey data from 528 businesses indicate that power outage duration has a positive significant effect on cost and technical efficiencies, and SMEs were more successful in doing so than larger ones. Finding a solution to the power outage issue while affecting negatively cost efficiency, seems to promote technical and scale efficiencies. Further, having a loans and/or a credit line appeared to have positive effects on technical and scale efficiencies.

\section{METHODOLOGY}

The survey research method was adopted in this study. A sample of 3 SMEs was randomly selected from the three geo-political zones of Rivers-state. The sample was obtained by employing the stratified sampling techniques. Out of one hundred and fifty (150) questionnaires administered to the respondents in these 3 companies, one hundred and twenty-four (124) were duly completed and returned. Thus, the analysis was based on the returned questionnaires only.

\section{ANALYSIS AND DISCUSSION OF RESULTS}

In analyzing the data collected from the respondents, multiple regression analysis was employed. The variables of the study can be expressed in algebraic form. Thus,

$$
\operatorname{Pr}=\mathrm{F}(\mathrm{E}, \mathrm{P}, \mathrm{S}
$$

Where

$\operatorname{Pr}=$ productivity which is proxied by efficiency, effectiveness, increase in sales, and customer satisfaction e.t.c

$\mathrm{E}=$ economic environment (monetary policies, interest rate, taxation)

$\mathrm{P}=$ political environment (elections, regulations, authority relationship)

$\mathrm{S}=$ socio-cultural environment (values, norms, belief, attitudes, religions)

In order to provide answer to the research questions and hypotheses that the economic, sociocultural and political environment has no implication on SMEs productivity, a regression line of $\mathrm{Y}=-85.31+4.69-3.01$ was obtained 


\section{Discussion of Results}

The finding shows that economic environment and political environment has a positive and significant implication on the productivity of SMEs in Rivers-State. Thus, the change in the economic environment will have a greater contribution on the Productivity of SMEs. The values are 0.93 and 0.68 . This indicates that the economic environment has $93 \%$ significant implication on the productivity of SMEs while the political environment has $68 \%$ impact. The value of $\mathrm{R}^{2}$ is 1.28 . This implies that external business environment has a $128 \%$ combined impact on the productivity of SMEs in Rivers-state.

\section{Conclusion}

From the findings in this study, the paper concluded that the productivity of SMEs is impacted more by changes in the political and economic environment than socio-cultural environment and this may have been caused by the failure of SMEs to continuously monitor and review their strategies in order to ensure that they are in conformity with market and environmental realities

\section{Recommendations}

i. SMEs should strategically engage in constant monitoring and conducting of environmental scanning.

ii. SMEs should learn to align their operational strategies with present market and environmental realities. This calls for a regular update and adjustment in strategies.

iii. Government should provide an urgent safety net for SMEs against undue taxation and other harsh economic policies that tend to hamper their productivity

\section{References}

Adebayo, I.O, Ogunyomi, P.O \& Ojodu, H.O (2005). Introduction to Business Management, Oshodi - Lagos, Abilejo Printing Press.

Chikwe G.C, Joel A, Achiole E.A (2015). The Impact of Regulatory Environment on the Effectiveness of Small and Medium Scale Enterprises: A Study of Selected Small and Medium Scale Enterprise in Owerri. Journal of Investment and Management 4 (6): 311-318

Felicia O. J, Olusoji G, Oluwakemi O \& Mofope A (2014). Effects of Socio-Cultural Realities on the Nigerian Small and Medium Sized Enterprises (SMEs): Case of Small and Medium Sized Enterprises in Lagos State. International Journal of Business and Management; Vol. 9, No. 1;

Lassana C., and Abdoulaye S (2013). Electric Power Outages and the Productivity of Small and Medium Enterprises in Senegal. Investment Climate And Business Environment Research Fund

Ogundele, O.J.K. (2005). Management and Organization Theory and Behaviour, Lagos, Nigeria, Sabte Book Series.

Oginni, B.O. (2010). Business Organic Management, 2nd ed. Somolu Lagos, Shecom Press Ltd.

Oginni, B.O \& Faseyiku, I.O. (2012). Fundamentals of Human Capital Management: A process approach, Mankore Print Ltd, Somolu - Lagos.

Olorunshola, J.A. (2003). Problems and Prospects of SMEs in Nigeria. Paper Presented at CBN Seminar on Small and Medium Industries Equity Investment Scheme (SMIEIS). www.cenbank.orglout!publications/guidelines/ $d f d / 2004 /$ smieris.pdf

Shane, S. (1993). Cultural Influences on National Rates of Innovation. Journal of Business Venturing, 8, 5973.http://dx.doi.org/10.1016/0883-9026(93)90011-S

Udechukwu, F. N. (2003). Survey of Small and Medium Scale Industries and their potentials in Nigeria. Paper Presented at Central Bank of Nigeria on Small and Medium Scale Industries Equity Investment Scheme (SMIEIS). www.centbank.orgloutlpublicationlguideline /dfdi2004lsmieis.pdf.

Wetherly, P., \& Otter, D. (2011). The Business Environment (2nd ed.). USA: Oxford University Press

World Bank. (2013). Republic of Bolivia - policies for increasing firms' formality and productivity. Washington, DC: The World Bank 